\title{
Semen Analysis and Morphological Study of Two Subsequent Generations of Dietary Protein Deficient Sprague Dawley Rats
}

\author{
Nosarieme Omoregie Abey*, Osaretin Albert Taiwo Ebuehi \\ Department of Biochemistry, College of Medicine, University of Lagos \\ Corresponding author email: nosariemeabey@gmail.com
}

Received: 08 July 2020 / Revised: 05 September 2020 / Accepted: 06 October 2020 / Published: 22 October 2020

\begin{abstract}
Adequate supply of dietary protein in regular diet is an important element of a proper nutritional status as it functions in the regulation of metabolic profiles signaling the reproductive axis. Reports have highlighted the association of the amount of protein in the diet to the functioning of hypothalamicpituitary-testis axis, however its intragenerational effects are yet to be adequately explored. The study aims to analyze the effect of protein deficient diet on parameters associated with male infertility from one generation to another. Female rats in four (4) groups $(\mathrm{n}=10)$ were fed different ration of protein in their diet (PD) as formulated: $21 \% \mathrm{PD}, 10 \% \mathrm{PD}, 5 \% \mathrm{PD}$ and control diet (rat chow), through gestation and lactation to first and second generations, while the male offspring sustained on the maternal diet after weaning were used for analysis. Sperm morphology and motility were evaluated using a light microscope and a computer-assisted semen analysis. The percentage of motile spermatozoa, morphological characteristics and histology in the deficient groups $(5 \%, 10 \% \mathrm{PD})$ appeared normal as compared to control in the first generation, showing an adaptive response while second generation was presented with significantly altered fertility parameters of the male offspring. It is suggested that in a deficiency status especially at the critical phase of development, certain deleterious effects which may be adaptive or phenotypic can serve to reduce the fertility efficiency in the male offspring at both $\mathrm{F}_{1}$ and $\mathrm{F}_{2^{-}}$generation.
\end{abstract}

Keywords: Semen, motility, protein deficiency, testicular morphology, testosterone.

\section{Introduction}

The male reproductive system is made up of certain internal structures (the testes, epididymis, vas deferens, prostate), and the external structures (the scrotum and penis). These structures are well-vascularized with many glands and ducts for the formation, storage, and release of sperm for fertilization, and to produce important androgens for male development [1]. The most important male androgen is testosterone, which is produced from Leydig cells in the testes. Testosterone plays an important role in stimulating the development of the Wolffian ducts in the male fetus, which become the testes, epididymis, vas deferens and seminal vesicles. Testosterone is also responsible for erythropoiesis, pubertal growth spurt, bone density, the closure of epiphyseal plates, deepening of the voice, increase in muscle mass, male physique development and libido. An imbalance in the hypothalamic-pituitary-gonadal axis can result in infertility and hypogonadism. Primary hypogonadism (hypergonadotropic hypogonadism) may be caused by gonadal failure to produce sufficient testosterone or spermatogenesis [1]. The existence of spermatozoa has been previously associated with male fertilizing ability, by recognizing that even though a man may be aroused or keenly interested in the opposite sex, this alone is not enough to guarantee the birth of offspring [2,3]. Spermatozoa are the only cells destined to be exported from the body. Thus, motility is an essential property of fertile spermatozoa. It enables ejaculated spermatozoa to traverse the female reproductive tract and reach the site of fertilization; essential for penetration of the outer 
parts of the oocyte including the zona pellucida. So, for the act of procreation to be fulfilled, the spermatozoa, as well as being motile, must also be sufficiently energetic to survive in the female tract for a certain period, presumably to attain their full potential [3,4].

The 2018 Global Nutrition Report reveals that the global burden of malnutrition is unacceptably high and now affects every country in the world [5]. At least 30 million men worldwide are infertile with the highest rates in Africa and Eastern Europe [6]. The maternal nutritional status during pregnancy is one of the most important environmental factors which might be expected to influence the course of pregnancy and other products of conception. Women, infants, children, and adolescents are at particular risk of malnutrition. Optimizing nutrition early in life is quite essential. Poverty amplifies the risk of, and risks from, malnutrition. People who are poor are more likely to be affected by different forms of malnutrition. Also, malnutrition increases health care costs, reduces productivity, and slows economic growth, which can perpetuate a cycle of poverty and ill-health [7].

Nutrition play a critical role in influencing reproductive function. Most studies indicate a positive association between metabolic perturbations and male fertility index, this in most cases has been explained as a direct correlation between reproductive control axis and the nutrient sensing capacity, as nutrients are signals that are capable of influencing phenotypic responses in individuals. Having assess to the right proportion or adequate supply of nutrient as a component of diet underlines the nutritional status of individuals [8].

During the critical physiological state (pregnancy), most women run unconsciously into a state of undernutrition with unknown consequences in subsequent generations. Studies have shown that sub-optimal protein consumption reduces the gonadal and endocrine function, and consequently male infertility [9], but little is known about exposure at intrauterinecondition, and if persistence of this malnutrition could cause the same deleterious effects or there is an adaptive shift in response. With focus on the male reproductive function in adolescents of first- and second-generation following exposure to protein deficient status, this study aimed to assess effects of protein deficiency on sperm quality parameters.

\section{Methodology}

\subsection{Experimental Design}

Ten (10) Sprague Dawley rats were each assigned into Four(groups) based on diet composition; Group A to D. A representing the severely deficient group received $5 \%$ protein diet, $\mathrm{B} ; 10 \%$ protein diet, C; 21\% protein diet (Markup for physiological status) and group $\mathrm{D}$; control diet (containing DRI percent for rat). The diet was formulated using non-purified constituents and standard formula, scored to requirements. The diet was formulated using non-purified constituents and standard formula, scored to requirements following adaptation from New Non-purified Diet (NTP-2000) for Rodents by Ghanto Rao, 1997 [10]. Constituents are slightly modified from Silas et al., [11], scored to proportion for the required protein ration in each group diet. All rats were maintained in clean capacious plastic cages $(\mathrm{n}=10$ per cage) under standard laboratory conditions following standard ethics guidelines of health research Act 2004, with ethical approval. The female cycles were monitored 3 weeks before breeding to preinform accurate time-mating with already certified reproductive male. Confirmed pregnant were separated to produce $F_{1}$-generation. Same procedure was repeated for $F_{1}$ - females to produce $\mathrm{F}_{2}$-generations. Weaning was done at postnatal day 28 , male and female progeny were separated using anogenital distance $(\leq 2.5 \mathrm{~mm})$ measured using calipers. The male progenies at each generation were maintained on their group diet for further investigation.

\subsection{Hormonal Assay}

At 16weeks of age, blood was collected into plain sample bottles through retro-orbital sinus using hematocrit capillary tubes, centrifuged at $2500 \mathrm{rpm}$ for 10 minutes. Serum was carefully collected and stored at $20^{\circ} \mathrm{C}$ for use. The testosterone levels were measured using commercially available Enzyme linked 
immunosorbent assay kit (Monobind Inc), following manufacturer's instruction.

\subsection{Sperm Quality Assessment}

Animals were sacrificed and caudal epididymis were harvested from each rat. The distal caudal epididymis is usually considered most preferable as it is the main storage site. Then the distal caudal epididymis was dissected free of other tissues (fatty or connective tissues) cut into pieces $(3-5 \mathrm{~mm})$ and picked into $1 \mathrm{ml}$ normal saline contained in a petri-dish (maintained at $37^{\circ} \mathrm{C}$ ). Sperm flowed into the medium, evidenced in the opacity of the surrounding medium. percentage sperm motility and concentration were measured while further preparations were made for morphological study. Sperm cell concentration was assessed by epididymal sperm count using hemocytometer and expressed as million/ml suspension [12]. Percentage motility was assessed by calculating motile spermatozoa per unit area. To assess the Sperm morphology of the cells, an aliquot of $20 \mu \mathrm{l}$ of the suspension containing sperm stained with $1 \%$ eosin, smeared on the slide, dried and viewed under microscope. Viability was based on differential count of spermatozoa that is stained (Viable) or unstained (Non-viable) [13]. The morphological appearance was observed at Mag X100 for expected and unexpected features.

\subsection{Histopathology}

Histological examination of rat testis in different group was carried out following slightly modified method of Ashidi et al., [14]. Testicular tissue removed, fixed for about 24hours, followed by series of dehydration with alcohol and xylene, clarification and paraffin embedding. Sample was sectioned by $5 \mu \mathrm{m}$ diameter microtome and placed on slides for hematoxylin and eosin staining, then examined at X400 magnification from different section. Sections of significant variation was photomicrographed.

Statistical Analysis: All data were presented as mean \pm SEM for all parameters, where necessary, using GraphPad prism 7.0. for Analysis of variance (ANOVA), followed by Turkey's test as post hoc, significance level is taken as $\mathrm{P}<0.05$.

\section{Results}

\subsection{Sperm Quality Assessment}

The quality of sperm in the deficient group remain insignificantly different from the groups fed with adequate proportion of protein in diet; control and 21\%PD (Figs. 1\&2) in the first generation. In the second generation, some of the key reproductive characteristics (Sperm count, motility and viability) were correspondingly compromised (Figs. 1\&2).

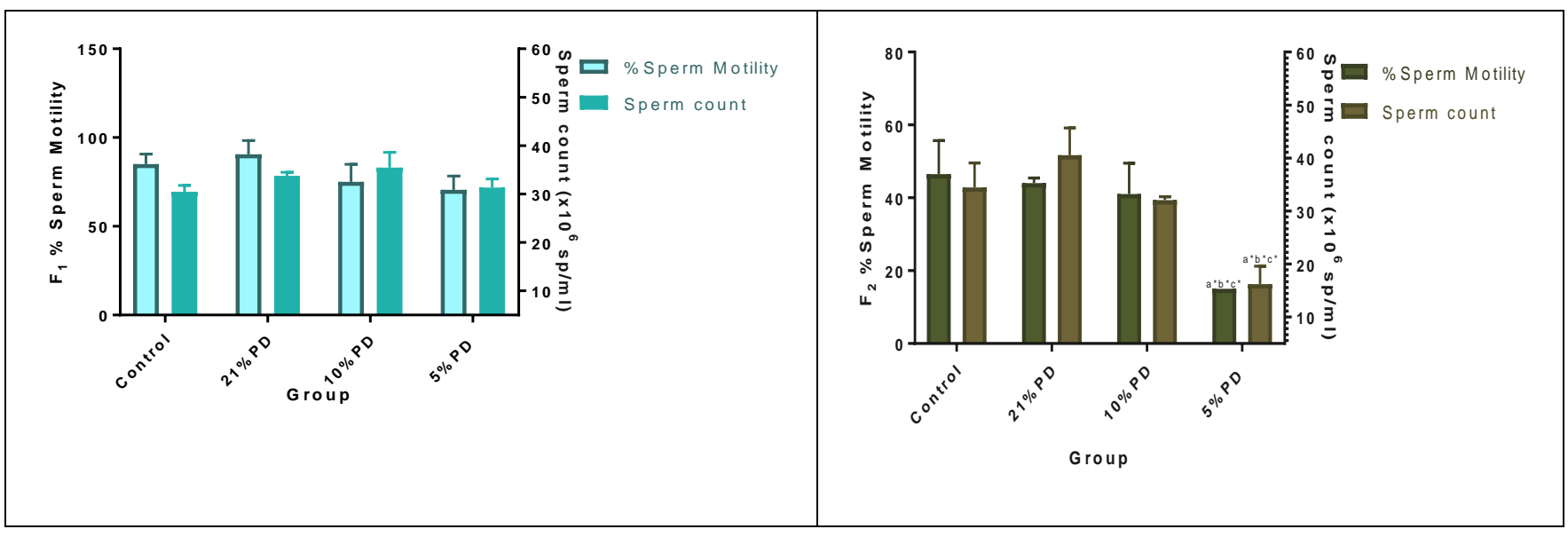

Figure 1: Mean Sperm Count and Motility score in each of the diet groups of rats of $F_{1}$ and $F_{2}$-generations

Data are expressed as mean \pm SEM, Control (standard rat chow containing 16-18\% Protein), 21\%PD (Upgraded daily recommended intake), $5 \%$ (Protein deficient diet), 10\% (Mild protein deficient diet).

a $<$ significantly different from $21 \%$ diet group and or control $>(* \mathrm{P}<0.05)$ 


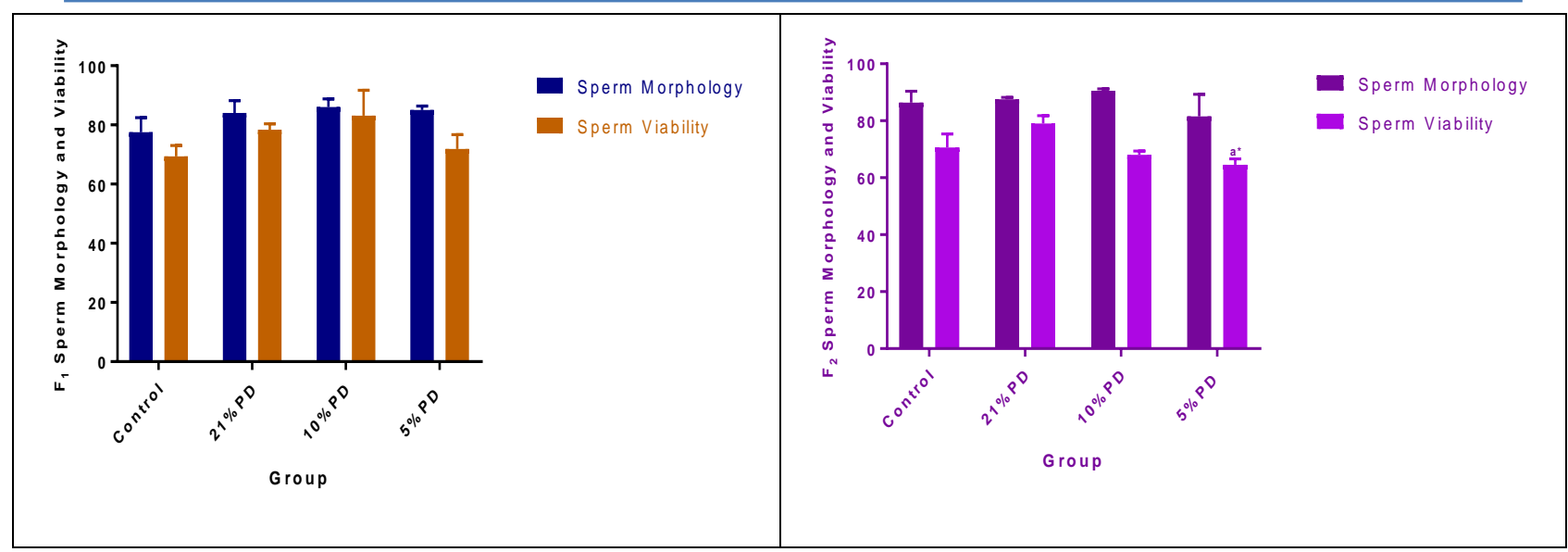

Figure 2: Mean Sperm Morphology and Viability Score in each of the diet groups of rats of F1 and F2generations

Data are expressed as mean \pm SEM, Control (standard rat chow containing 16-18\% Protein), 21\%PD (Upgraded daily recommended intake), $5 \%$ (Protein deficient diet), 10\% (Mild protein deficient diet).

a $<$ significantly different from $21 \%$ diet group and or control $>(* \mathrm{P}<0.05)$

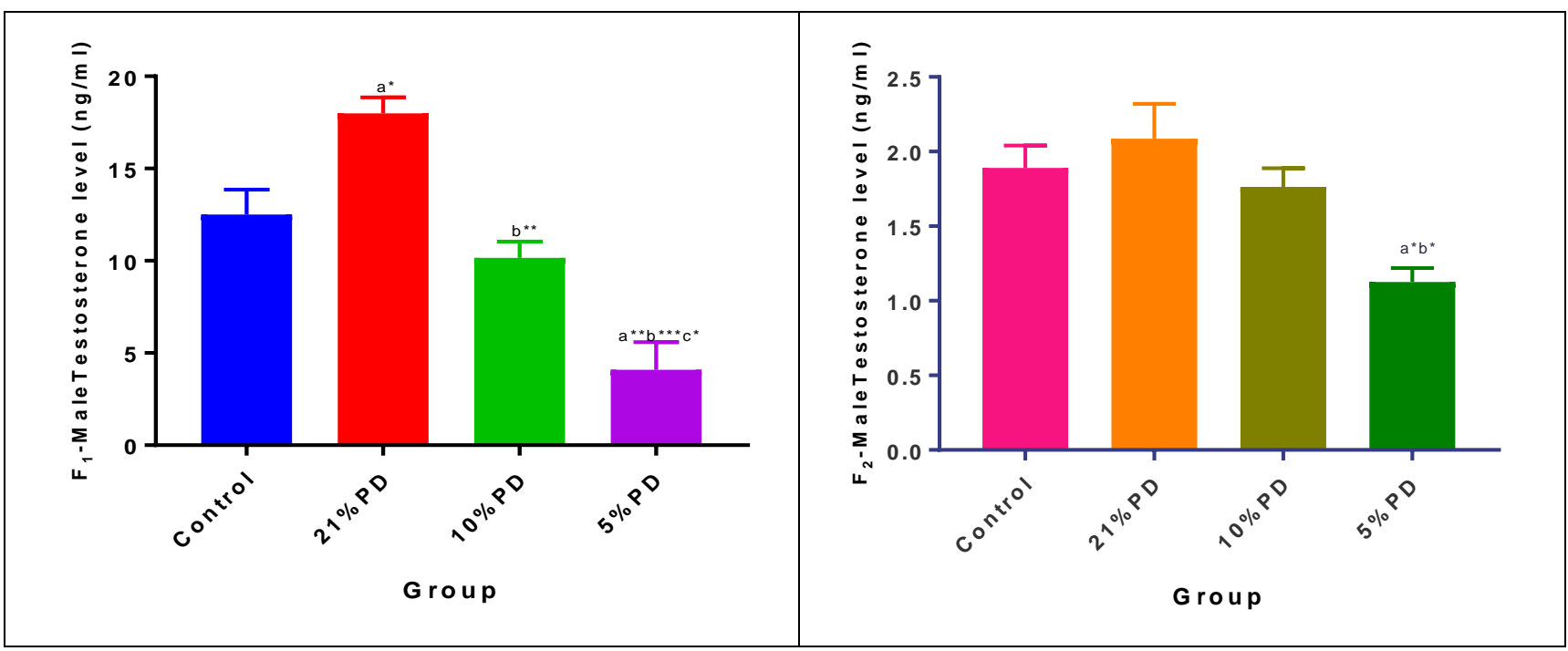

Figure 3: Mean Testosterone concentration $(\mathrm{ng} / \mathrm{ml})$ in each of the diet groups of rats of $F_{1}$ and $F_{2}$-generations

Data are expressed as mean \pm SEM, Control (standard rat chow containing 16-18\% Protein), 21\%PD (Upgraded daily recommended intake), $5 \%$ (Protein deficient diet), 10\% (Mild protein deficient diet).

a $<$ significantly different from control diet group $>$

$\mathrm{b}<$ significantly different from the $21 \%$ diet group $>$

$\mathrm{c}<$ significantly different from the $10 \%$ diet group $>(* \mathrm{P}<0.05, * * \mathrm{P}<0.001, * * * \mathrm{P}<0.001>$

\subsection{Hormonal Assay}

The serum testosterone level in both deficient groups $(5 \%$ and $10 \% \mathrm{PD})$ of the first generation $\left(\mathrm{F}_{1}\right)$ were significantly reduced, while the second generation $\left(\mathrm{F}_{2}\right)$ presented the $5 \% \mathrm{PD}$ group with hormonal compromise, and $10 \% \mathrm{PD}$ group showing an adaptive response (Fig 3), with no significant difference from the reference group.

\subsection{Histopathological Examination}

Figures 4-6 are presented with $\mathrm{F}_{2}$-generation photomicrographs of testis in each diet group of rats fed with different ration of protein, with no marked histological alteration in Control (Fig 4) and $21 \% \mathrm{PD}$ (Fig 5), while the deficient group showed apparent pathological changes (Figs. 6 \& 7). $F_{1}$-generation photomicrograph reports proper characterization of testicular morphology 
with normal cellular disposition, lumen containing matured sperm cells, proliferating centripetally from spermatozoa in the basement membrane and the sustentacular cells are found within interstitial spaces. No apparent pathological alterations, across groups.

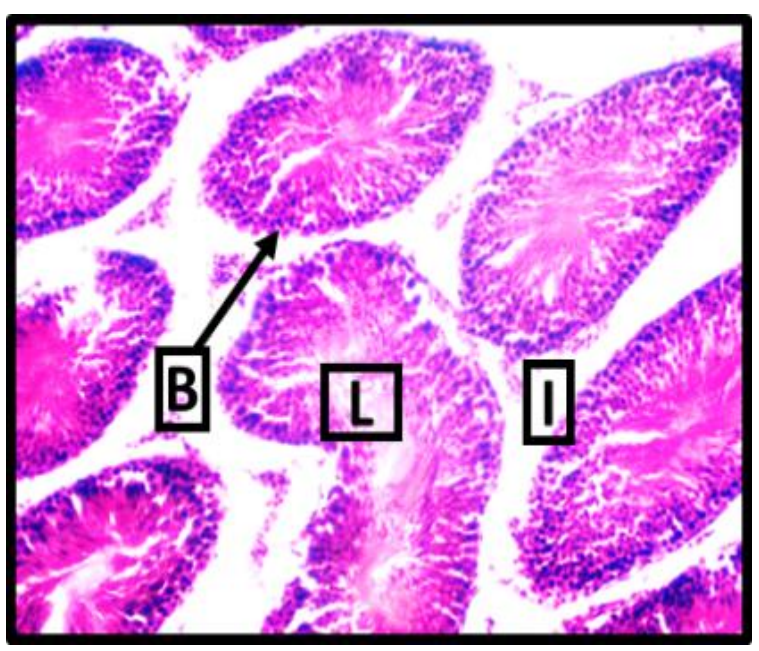

Figure 4: Photomicrograph of Sprague Dawley rat Testis (Control)

Presented photomicrograph of the testes of experimental animal showing a transverse section of the seminiferous tubule. The figure shows the lumen (L) of the seminiferous tubule, the basement membrane (B) and the interstitial space (I). The lumen contains/house matured sperm cells proliferated centripetally from the spermatozoa in the basement membrane while the sustentacular cells are found within the interstitial spaces. The photomicrograph appears normal with no marked changes in the histology presentation.

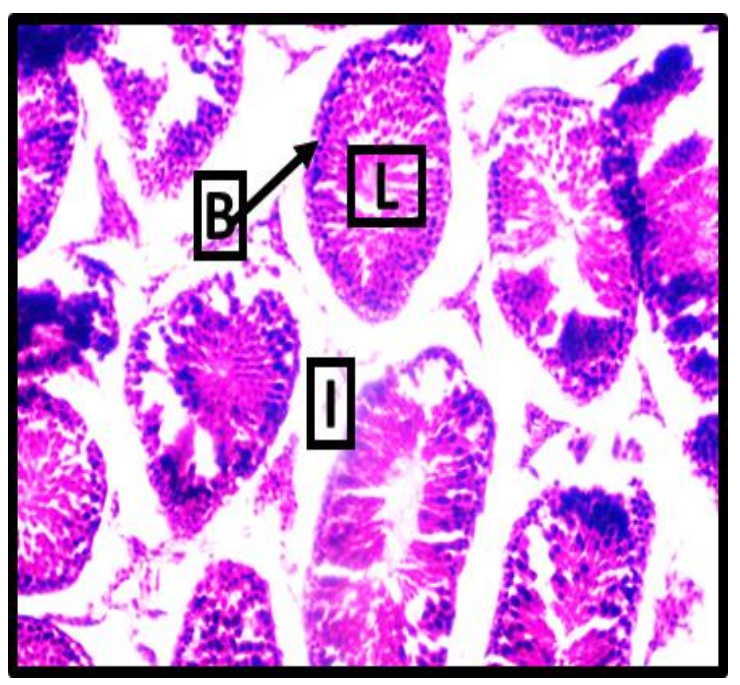

Figure 5: Photomicrograph of 21\% PD Sprague Dawley rat Testis
The testis shows the lumen (L) of the seminiferous tubule, the basement membrane (B) and the interstitial space (I). The figure above shows proper characterization of testicular histomorphology with normal cellular disposition and staining intensity with no apparent pathological alteration.

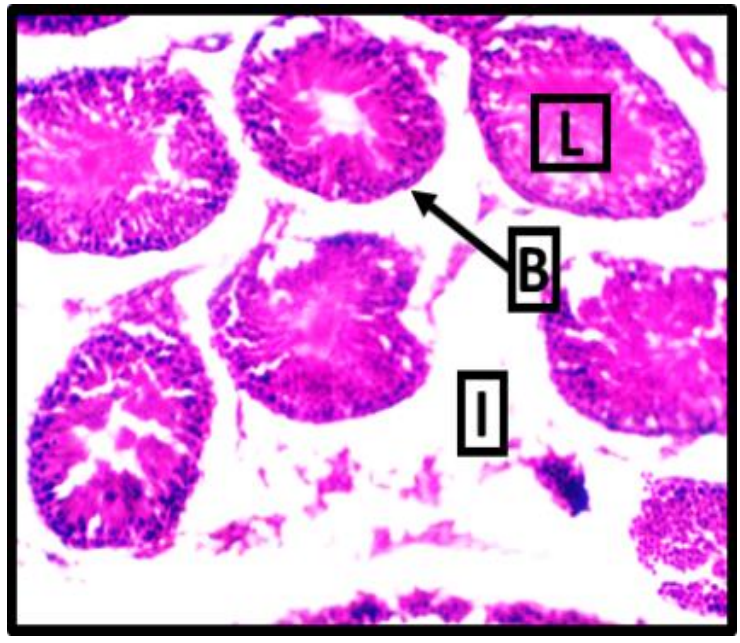

Figure 6: Photomicrograph of 10\%PD Sprague Dawley rat Testis

Presented with photomicrograph of the testes showing a transverse section of the seminiferous tubule. the lumen $(\mathrm{L})$ of the seminiferous tubule, the basement membrane (B) and the interstitial space (I). The photomicrograph present with enlarged interstitial space and shrunken seminiferous tubule.

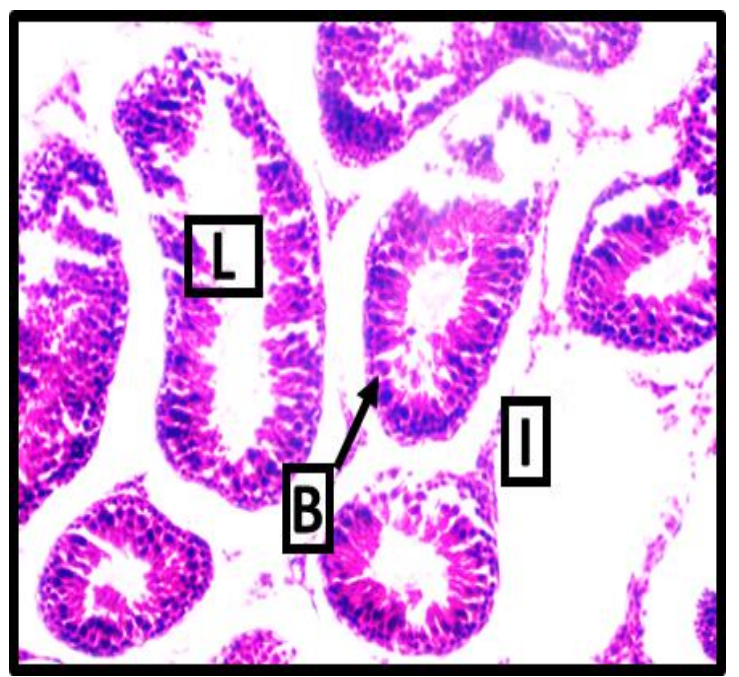

Figure 7: Photomicrograph of 5\% PD Sprague Dawley rat Testis

Showing a transverse section of the seminiferous tubule. the lumen $(\mathrm{L})$ of the seminiferous tubule, 
the basement membrane (B) and the interstitial space (I). Photomicrograph present with enlarged lumen, enlarged interstitial space and perturbation in histomorphology.

\section{Discussion}

The access to right proportion or adequate supply of diet underlies the nutritional status of individuals. Nutrition play key role in influencing reproductive function. The maintenance of reproductive status critically depends on proper functioning of the testis. The sperm morphology and testicular cytoarchitecture, are essential parameters that reflects the degree of normality and maturity of sperm [15]. Defects in the appearance of sperm parts, has been classified as primary defect of spermatogenesis [16], which results in testicular degeneration. Low protein diet has been earlier reported by Ozegbe and Omirinde [17], to induce changes in morphology of seminiferous tubules, this is in agreement with the findings from this study, as the severely deficient group $(5 \%$ protein diet) displayed changes in the characterization of the sperm especially in the second generation. The observed insignificant difference in morphology of first generation may be due in part to an adaptive shift in metabolic response to cater for the deficiency, since the serum testosterone level was markedly reduced. Persistence to $\mathrm{F}_{2}$-generation displayed optimal fertility dysfunctions as stated in the result section. Earlier reported by Sharaf et al., [18], states that the pathological changes due to protein malnourishment may be attributed to lipid peroxidation, free radicals and hormone changes in damaged cells, thus, altering testicular function [19], this may provide an underlying mechanism for the observed result. Mylchreest et al., and Ashidi et al., [20, 14], have previously reported an association between increased epidydimal sperm number to elevated level of testosterone in rats, also the percentage motility count has been related to quality of protein contents in food consumed [21] as evidenced in the protein deficient group (5\% and $10 \% \mathrm{PD})$. The Pathological alterations evident in the malnourished groups in the second generation, characterized by enlarged interstitial space and shrunken seminiferous tubules in the testis as well as endocrine dysfunction in $F_{1}$ and $F_{2-}$ generations suggests deleterious imprints especially with the modification of cellular architecture and structural reorganization.

\section{Conclusion}

The study presents a summary that in a protein deficiency status, especially at the critical phase of development, certain deleterious effects which may be adaptive or phenotypic can serve to reduce the fertility efficiency in male offspring. Adaptive response has been fundamental to reorganization and defects, in an attempt to cater for inadequacy or sub-optimal nutritional condition. As displayed in this research, $\mathrm{F}_{2^{-}}$ generation with enlarged interstitial space and shrunken seminiferous tubule, compromised hormonal function are evidence of critical defects in the reproductive system of male offspring in intragenerational exposure to protein deficient diet. This research provides a deeper insight into intragenerational effects of protein deficiency on reproductive parameters of male Sprague Dawley rats exposed at the critical period of development. It can therefore be concluded that protein diet is important for the effective development and functioning of the male reproductive module, from one generation to the other, exposure at the critical stage of development (perinatally) may impair proper reproductive outcome at latter age.

\section{Declarations}

\subsection{Acknowledgment}

We acknowledge the technical support of $\mathrm{Mr}$. Dike physiology Department, College of Medicine, University of Lagos

\subsection{Ethical Approval}

Ethical approval was sought for and approved by the Health Research Ethics Committee (HREC) of College of Medicine University of Lagos (REC 11), Nigeria, following the submission and inspection of study design and detailed protocol in accordance with the guidelines of health research Act 2004, for standard care and use of laboratory animal models. 


\subsection{Competing Interests}

[13] N. N. Oliveira,. P. M. Félix, M. A. R. Pereira, T. C. S.

There is no conflict of interest in this research.

\section{How to Cite this Article:}

N. O. Abey and O. A. T. Ebuehi, "Semen Analysis and Morphological Study of Two Subsequent Generations of Dietary Protein Deficient Sprague Dawley Rats", Int. Ann. Sci., vol. 10, no. 1, pp. 85-91, Oct. 2020. https://doi.org/10.21467/ias.10.1.85-91

\section{References}

[1] P. Gurung, E. Yetiskul \& I. Jialal, "Physiology, Male Reproductive System", In: StatPearls [Internet]. Treasure Island (FL), StatPearls Publishing; Jan, 2020. https://www.ncbi.nlm.nih.gov/books/NBK538429/

[2] T. Mann \& C. Lutwak-Mann, "Male Reproductive Function and the Composition of Semen: General Considerations" Male Reproductive Function and Semen, pp 1-37. Jan, 1981. https://doi.org/10.1007/9781-4471-1300-3_1

[3] S. Vijayaraghavan, "Sperm Motility: Patterns and Regulation", Introduction to Mammalian Reproduction. Springer, Chap. 5, pp. 79-91, Jan, 2003 https://doi.org/10.1007/978-1-4615-0273-9_5

[4] V. Sapanidou, I. Taitzoglou, I. Tsakmakidis, I Kourtzelis, D. Fletouris, A. Theodoridis, S. Lavrentiadou \& M. Tsantarliotou, "Protective effect of crocetin on bovine spermatozoa against oxidative stress during in vitro fertilization", Andrology, vol.4, no. 6 , pp. 1138-1149. Nov, 2016. doi:10.1111/andr.12248

[5] World Health Organization. "Global Nutrition Report", Nov. 2018, Retrieved from: https://www.who.int/nutrition/globalnutritionreport/en/.

[6] A. Agarwal, A. Mulgund, A. Hamada, M.R. Chyatte, "A unique view on male infertility around the globe", Reprod Biol Endocrinol. Vol. 13, pp37. Apr, 2015. https://doi.org/10.1186/s12958-015-0032-1

[7] World Health Organization. "Malnutrition". Apr, 2020. Retrieved from: https://www.who.int/news-room/factsheets/detail/malnutrition.

[8] G. Wu, B. Imhoff-Kunsch, A. W. Girardc "Biological Mechanisms for Nutritional Regulation of Maternal Health and Fetal Development", Paediatric and Perinatal Epidemiology, vol. 26 no S1, pp 4-26, Jun, 2012, https://doi.org/10.1111/j.1365-

3016.2012.01291.x

[9] P. K. Ajuogu, M. A. Al-Aqbi, R. A. Hart, M. Wolden, N.A. Smart, \& J. R. McFarlane, "The effect of dietary protein intake on factors associated with male infertility: A systematic literature review and meta-analysis of animal clinical trials in rats", Nutrition and Health, vol.26, no 1 , pp 1-12, Jan, 2020. https://doi.org/10.1177/0260106019900731

[10] N.R. Rao, "New Nonpurified Diet (NTP-2000) for Rodents in the National Toxicology Program's Toxicology and Carcinogenesis Studies", The Journal of Nutrition, Vol. 127, no 5, pp 842S-846S, May, 1997. https://doi.org/10.1093/jn/127.5.842S.

[11] A. F. Silas, A.O. Ayorinde, E. Daisy, O.M. Sogunle, O.B. Oluwole, and N.G. Elemo "Effect of stocking density and quantitative feed restriction on growth performance, digestibility, haematological characteristics and cost of starting broiler chicks", $J$. Anim. Health \& Prod., vol 2, no 4, pp 60-64, Oct, 2014. http://dx.doi.org/10.14737/journal.jahp/2014/2.4.60.64

[12] Y. Raji, S.O. Akinsomisoye, T. M. Salman, "Antispermatolgenic activity of Morinda lucida extract in male rats", Asian J. Androl. Vol.7 no 4, pp 405-410, Dec, 2005. doi:10.1111/j.1745-7262.2005.00051.x
Rocha, L. G. P., Miranda, J. R., Zangeronimo, M. G., ..., R. V. de Sousa, "Sperm Quality and Testicular Histomorphometry of Wistar Rats Supplemented with Extract and Fractions of Fruit of Tribulus terrestris L", Brazilian Archives of Biology and Technology, vol. 58, no 6, pp 891-897. Dec, 2015. http://dx.doi.org/10.1590/S1516-89132015060278.

[14] J. S. Ashidi, F. O. Owagboriaye, F.B. Yaya, D.E. Payne, O.I. Lawal, \& S.O. Owa, "Assessment of reproductive function in male albino rat fed dietary meal supplemented with Mucuna pruriens seed powder", Heliyon, vol.5, no 10, Oct, 2019.

[15] J.O. Omirinde, P. C. Ozegbe, M. O. Oyeyemi. "Comparative evaluation of the sperm characteristics and morphology of adult Wistar rats fed either low or normal protein-energy diets and orally dosed with aqueous Cuscuta australis extracts". Niger. J. Physiol. Sci, vol. 29 no 1 pp 055-061, Jun, 2014. PMID: 26196567, https://pubmed.ncbi.nlm.nih.gov/26196567/

[16] F. Tüttelmann, C. Ruckert \& Albrecht Röpke, "Disorders of spermatogenesis, Perspectives for novel genetic Genet. vol. 30, no. 1, pp. 12-20, Feb, 2018. doi: 10.1007/s11825-018-0181-7

[17] P.C. Ozegbe, and J.O. Omirinde, "Comparative morphophysiological evaluation of the testis of adult Wistar rats fed low protein-energy diet and dosed with aqueous extracts of Cuscuta australis", Niger. J. Physiol. Sci., vol. 27, no 2, pp 149-155, Dec, 2012. https://pubmed.ncbi.nlm.nih.gov/23652229/

[18] H.A. Sharaf, F.A. Morsy, N.M. Shaffie, A.T.M. ElShennawy, "Histological and Histochemical Study on the Protective Effect of Curcumin on Ultraviolet Irradiation Induced Testicular Damage in Albino Rats", J Cytol Histol vol. 3 no 6, pp 159. Nov, 2012, DOI: $10.4172 / 2157-7099.1000159$

[19] G. L. Rodríguez-González, L. A. Reyes-Castro, C. C. Vega, L Boeck, C. Ibanez, P. W. Nathanielsz, F. Larrea, E. Zambrano, "Accelerated aging of reproductive capacity in male rat offspring of protein-restricted mothers is associated with increased testicular and sperm oxidative stress". Age (Dordr). vol. 36, no. 6, pp. 9721, Oct, 2014. doi:10.1007/s11357-014-9721-5

[20] E. Mylchreest, M. Sar, D. G. Wallace \& P.M.D. Foster, "Fetal testosterone insufficiency and abnormal proliferation of Leydig cells and gonocytes in rats exposed to di(n-butyl) phthalate," Reproductive Toxicology. Vol 16, no. 1, pp. 19-28, Jan, 2002. https://doi.org/10.1016/S0890-6238(01)00201-5

[21] V. B. Mutwedu, R. B. B. Ayagirwe, S. B. Bacigale, L. M. Mwema, S. Butseme, T. Kashosi, B. Mitima, G. J. Manyawu \& A. W. Nyongesa, "Effect of dietary inclusion of small quantities of Mucuna pruriens seed biochemical parameters in rabbit bucks (Oryctolagus cuniculus)." Trop Anim Health Prod. vol. 51, no. 5, pp. 1195-1202, Jun, 2019. doi:10.1007/s11250-019-018082.

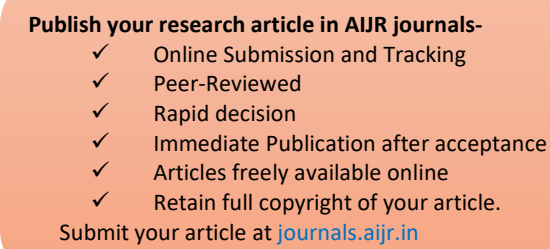
https://doi.org/10.1016/j.heliyon.2019.e02716 diagnostics after 20 years of unchanged routine," Med meal on sexual behavior, semen characteristics, and 